\title{
Editorial
}

\section{TIC en la \\ educación \\ del futuro}

DOI: 10.29236/sistemas.n158a1

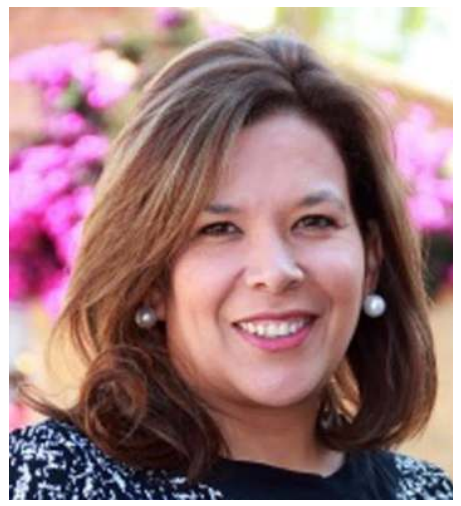

\section{Yasbley Segovia Cifuentes}

Luego de lo vivido en el año 2020 ante el impacto global producido por el COVID-19, la retrospectiva y la previsión se convirtieron en el fundamento para que distintas organizaciones mundiales de reconocida trayectoria nos presenten múltiples versiones, escenarios o formas alternativas para imaginarnos el futuro de la educación. Apor- tes que nos pueden servir como punto de partida para tomar acciones.

La Organización para la Cooperación y el Desarrollo Económicos (OCDE), nos presenta distintos escenarios para explorar el futuro de la educación: i) la escuela extendida en donde la internacionalización 
y la tecnología permiten un aprendizaje individualizado, ii) la escuela como centro abierto de aprendizaje conectado con su comunidad, promoviendo el compromiso cívico y, iii) la innovación social y el aprendizaje a la medida, en donde las distinciones entre lo formal e informal ya no son válidas.

Otros contenidos contemplan los futuros de la educación de la Organización de las Naciones Unidas para la Educación, la Ciencia y la Cultura (UNESCO), cuyo objetivo es repensar la educación y dar forma al futuro, catalizando un debate mundial sobre cómo hay que replantear el conocimiento, la educación y el aprendizaje en un mundo de creciente complejidad, incertidumbre y precariedad.

La gran mayoría de estudios, coinciden en recomendar la preparación de nuestros sistemas educativos para lo que pueda venir, considerando no solo los cambios que parecen más probables, sino los que no esperamos.

Los expertos recomiendan que la forma de comprender el futuro es a través del diálogo, por ello, tan pertinente la temática del foro: Futuro de la educación e incertidumbre, encuentro en el que un decano, tres profesores universitarios y una representante de los colegios colombianos se pronunciaron sobre el particular. Los invitados, de distintos niveles y roles en la comunidad educativa, resolvieron inquietudes sobre los escenarios que debemos fundamentar para prepararnos en torno a las implicaciones clave y las tensiones que de allí surgen; a las acciones que se deben realizar para aprovechar las ventajas, cada vez más evidentes de la tecnología y lo que significa estar preparado en un contexto tan desafiante. En las conclusiones se refirieron a cómo reimaginar la formación de las nuevas generaciones de profesionales.

La columna Aprender haciendo, colaborativamente, de Ignacio Trejos Zelaya hace un recuento histórico de los cambios en la industria tecnológica y las repercusiones en la formación de profesionales de dicho sector. Surge así una propuesta educativa innovadora que responde a la formación de ingenieros con un enfoque centrado en el estudiante, para que de manera colaborativa resuelvan en forma vivencial problemas integradores, multidisciplinarios y multifacéticos. Lo que ha generado un impacto tangible en la sociedad costarricense.

Los artículos en esta edición, relacionan diversos aprendizajes derivados de la crisis que nos trajo la pandemia y que invitan con ahínco hacia la sostenibilidad y la búsqueda de un planeta en equilibrio; promueven una educación emocional a lo largo de la vida de la persona, como imperativo para el ejercicio de una ciudadanía activa ante las distintas problemáticas que vive 
nuestra sociedad con sus impactos económicos y sociales.

Así mismo, nos recuerdan los desafíos para la educación, además de las diferentes consideraciones sobre el papel que han jugado los observatorios de las tecnologías en la educación superior. También, nos invitan a mirar desde el interior de nuestras instituciones las relaciones con las tecnologías emergentes.

Andrés Almanza nos comparte su investigación: El futuro de la educación, tema abordado recientemente por distintos entes multilaterales, tales como el Foro Económico Mundial, la Organización para la Cooperación y el Desarrollo Económico (OECD), la Organización de las Naciones Unidas para la Educación, la Ciencia y la Cultura (Unesco), el Instituto Internacional para la Educación Superior en América Latina y El Caribe (IESLAC) y la Organización de Estados
Iberoamericanos para la Educación, la Ciencia y la Cultura (OEI). Dicha investigación cierra con diez ideas clave, en que el autor unifica los puntos más relevantes de los distintos escritos analizados y nos confronta a repensar la educación del mañana de manera inmediata.

Para finalizar, no pueden dejar de leer la maravillosa entrevista al maestro Albert Sangrà quien a lo largo de la conversación muestra su pasión en el ejercicio profesional y las tendencias relacionadas con la modalidad dual, la gamificación, las brechas tecnológicas y el emprendimiento digital, entre otros asuntos.

Apreciados lectores, la recomendación es leer cada sección de esta revista, cuya temática merece toda nuestra atención ante una necesidad imperante: PENSAR Y PREPARAR LA EDUCACIÓN DEL FUTURO. 管

Yasbley Segovia Cifuentes. Doctora en Educación de la Universidad de Navarra en España, Magíster en Tecnologías de la Información Aplicadas a la Educación de la Universidad Pedagógica de Colombia. Directora del Centro de Tecnologías para la Academia, líder del proyecto Unisabana e-Learning e investigadora del grupo de investigación Tecnologías para la Academia-Proventus de la Universidad de La Sabana. Editor técnico para esta edición de la revista Sistemas de la Asociación Colombiana de Ingenieros de Sistemas (Acis). 
